\title{
Experimental and analytical analysis of reinforced concrete columns strengthened with CFRP
}

\author{
Carlos Valbson dos Santos Araújo ${ }^{1}$ (1) Ricardo José Carvalho Silva ${ }^{2}$
}

Received: 26 May 2016/Accepted: 20 September 2016/Published online: 27 September 2016

(C) Springer International Publishing Switzerland 2016

\begin{abstract}
The technology of the Construction Industry is advancing constantly. Every year, new materials, equipment, and building techniques are introduced. In the specific case of reinforced and pre-stressed concrete structures, the innovations have contributed to the improvement of the properties of the concrete and the durability of the structures that incorporate this material. These advances are not restricted to the construction of new structures, however, and it is important to recognize the need to recuperate structural elements or increase their resistance, which has provided incentives for the improvement of techniques of structural reinforcement. In this context, the present study used a combined theoretical and experimental approach for the investigation of the effectiveness of the reinforcement of concrete columns by jacketing them with polymer mantles strengthened with carbon fibers. The analyses aimed to determine the effectiveness of the mantles in terms of the increase in resistance to axial compression and contribute to the understanding of the structural behavior of columns strengthened using this technique. To this end, centered axial compression tests were run on five short reinforced concrete columns, including one control column and four experimental columns with different reinforcement ratios. Numerical simulations were also run in the Abaqus software to determine
\end{abstract}

Carlos Valbson dos Santos Araújo

carlos.valbson.araujo@gmail.com

Ricardo José Carvalho Silva ricardo.carvalho222@gmail.com

1 Faculdade de Tecnologia, Universidade de Brasília (UnB-PECC), Brasília, Brazil

2 Departamento de Engenharia Civil, Universidade Estadual Vale do Acaraú, Fortaleza, Ceará, Brazil the distribution of tensions inside the columns. The sum of the evidence was analyzed and it was verified that the strengthening used in the columns increased considerably their resistant capacities, thus the gain in this capacity was directly proportional to the value of the used strengthening rate- the column with the biggest strengthening rate bore a last load $42.8 \%$ bigger than the one borne by the column of reference, with no strengthening. From these data, it was possible to obtain a simple predictive model of the increase in resistance capacity of columns strengthened with carbon fibers.

Keywords Reinforced concrete columns - Structural reinforcement $\cdot$ Carbon fiber reinforced polymer . Centered axial compression

\section{Introduction}

In recent decades, there have been major technological advances in the use of reinforced and pre-stressed concrete in the construction industry, contributing to the general quality of buildings, which has permitted the construction of more durable and elegant projects, with record-breaking heights, spans and cantilevers. Even so, intervention is often required in order to recuperate structural elements or increase their resistance. In this case, the development of improved techniques of structural reinforcement will contribute to the lifespan and performance of many architectural projects.

The columns are among the most important elements of a structure, given that their rupture can lead to the destruction of the whole building. There are a number of different types of reinforcement for existing concrete, including shotcrete or high resistance concrete with 
supplementary reinforcement, the casing of existing columns with steel plates, the use of concrete with the addition of steel fibers and, more recently, jacketing with a mantle of reinforced polymer fibers (RPF). The latter approach presents innumerable advantages, such as the easy and rapid application of the jacketing, and the fact that it does not increase the transversal section of the columns.

Although the high cost of the CFRPs, compared to the cost of other structural strengthening materials, can be considered the main limitation for its use, when the whole costs during the lifespan of the structures are taken into consideration, the durability offered by the strengthened polymers can turn them into a very competitive option, by offering a great benefit-cost ratio. Considering the need for a better understanding of the structural behavior of the strengthened columns, the present study provides a theoretical and experimental analysis of the reinforcement using jackets of carbon fiber reinforced polymer (CFRP), with the primary objective of determining the increase in resistance to axial compression in short columns of reinforced concrete (RC) jacketed with CFRP.

\section{Behavior of reinforced concrete columns strengthened with CFRP}

\section{Reinforcement with composite materials}

Gibson [1] classified structural materials as metals, polymers, ceramics or composites, the latter being composed of some combination of the former three, forming a macroscopic structural arrangement, with two or more distinct phases. Composite materials are thus composed of a matrix, bundles of bars or fibers, and in some cases, an additive. Figure 1 illustrates the macroscopic characteristics of FRP systems.

Nowadays, composites reinforced with fibers are widely used for the reinforcement of concrete structures. The advantages of this method include the enhanced mechanical resistance of the material, combined with its low

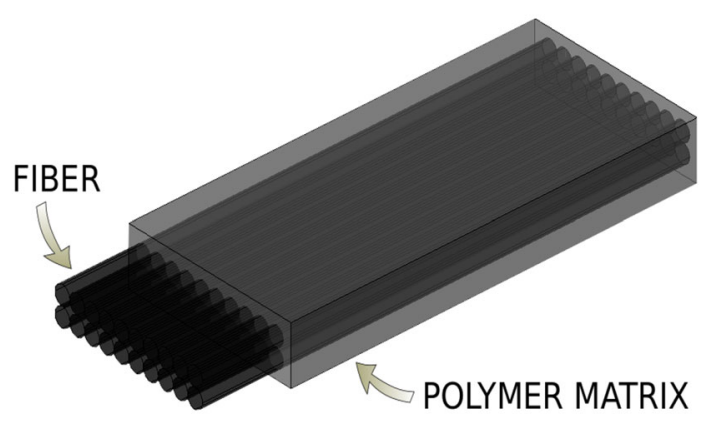

Fig. 1 Characteristics of FRP systems density, good durability and reduced maintenance due to its resistance to corrosion. The material can also be easily concealed and its application is relatively simple in comparison with other, more traditional types of reinforcement. It nevertheless has a number of disadvantages, starting with its current high price and its sensitivity to high temperatures and ultraviolet rays, due to its polymeric matrix, as well as the need for qualified technical supervision to guarantee the quality of the system.

Carbon fibers are produced by the oxidation of organic precursors, such as polyacrylonitrile (PAN), or from derivatives of petroleum or coal (pitch), which are processed at high temperatures, of around $1000-1500{ }^{\circ} \mathrm{C}$, or as high as $3000{ }^{\circ} \mathrm{C}$ for graphite fibers. Following this thermal processing, the carbon atoms in the fibers will be aligned perfectly in the material, and it is this alignment that confers the end product with its considerable mechanical resistance.

In CFRP composites, the carbon fibers are responsible for the mechanical resistance of the system, with the polymer matrix transferring the tensions of the concrete substrate to the rest of the system. To achieve this, the matrix must have a rupture extension longer than that of the fibers, to ensure that the fibers maintain their load capacity, even when the tension of the fibers has reached its limit of resistance. The application of the CFRP layers follows a relatively straightforward sequence (Fig. 2).

\section{Confinement of the concrete}

The confinement of the concrete is undoubtedly the procedure that is most effective for the reinforcement of columns. This increases considerably the resistance capacity and ductility of an existing column, while increasing the transverse sections of these elements only slightly. The confinement works by applying pressure transversally to the longitudinal axis of the column, restricting the lateral expansion of the concrete, which can be achieved by the application of transverse pre-stressing or confined expansive materials (active confinement) or by the application of steel plates, struts or FRP jackets (passive confinement).

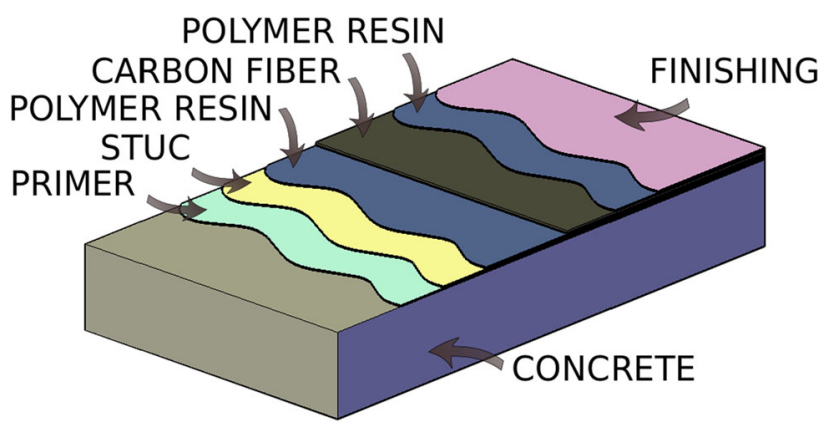

Fig. 2 Sequence of application of CFRP mantles 
Behavior of the confined concrete under uniaxial compression

Standard concretes contain approximately $75 \%$ of aggregates of different sizes [2], which make up the rigid component of this type of concrete (in high resistance concretes, the cement is more resistant than the aggregates), through which the compressive forces are directed (see Fig. 3a). Lateral components are necessary for equilibrium, and in the unconfined concrete, this is provided by the cohesion of the cement (see Fig. 3b). When the load exceeds the cohesive force, micro-cracks will appear between the aggregates and the cement (see Fig. 3c). As the load increases, in the absence of lateral components to ensure equilibrium, the concrete will fracture, fissuring parallel to the application of the load. With confinement, however, there is an increase in cohesion, which will guarantee the equilibrium of the load forces, increasing the resistance of the concrete to compression (see Fig. 3d).

The increase in cohesion is due to the lateral pressures created by the confinement. In studies such as those of Richart et al. [3] and Balmer [4], axial compression tests were conducted on concrete confined with fluids and transverse reinforcement, which showed that the resistance to axial compression and the final deformation time of the concrete both increase in the presence of confined pressures.

\section{Confinement with FRP jackets}

Major differences exist between the behavior of concretes confined with steel and those confined with FRP [5]. Research on confined concrete has shown a minor smoothing of the tension-deformation diagram when the concrete reaches its peak resistance $\left(\mathrm{f}_{\mathrm{cc}}\right)$, observed as soon as the transverse reinforcement flows. The diagram then proceeds with a decreasing slope and presents a rupture tension lower than $\mathrm{f}_{\mathrm{cc}}$, coinciding with the rupture of the transverse cladding (see Fig. 4). The low rupture deformation and the lack of a flow threshold in the concrete jacketed with FRP results in increasing pressure up to the rupture point, producing a bilinear tension-deformation diagram, as shown on Fig. 4 [6].

\section{Experimental design}

\section{Initial considerations}

The experimental study was based on physical tests of axial compression conducted on five RC columns, including one control column and four with different configurations of reinforcement. The tests were conducted in the Laboratory of Materials and Structures of the Vale do Acaraú State University in Ceará, Brazil, where the compressive strength tests were also run.

\section{Materials}

The concrete used in the test columns was produced in a central mix system, dosed to a compression resistance of approximately $30 \mathrm{MPa}$ after 28 days. The mean compressive strength $\left(f_{c}\right)$ was found from 4 samples, tested according to the ABNT rules NBR:5739 [7], and its value is shown in Table 1. The mean tensile strength of the concrete $\left(\mathrm{f}_{\mathrm{ct}, \mathrm{m}}\right)$ and the initial tangential elasticity $\left(\mathrm{E}_{\mathrm{ci}}\right)$ and drying $\left(\mathrm{E}_{\mathrm{cs}}\right)$ moduli were estimated using the formulas provided by the Brazilian norms association [8]. These values are also shown in Table 1.

The longitudinal reinforcement rods were made of CA50 type ribbed steel bars with a diameter of $8.0 \mathrm{~mm}$, while the transverse bars were made of CA-60 type steel bars (a)

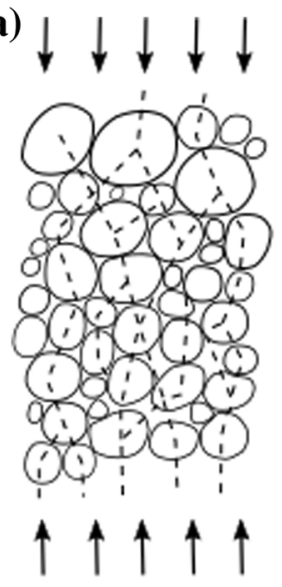

(b)

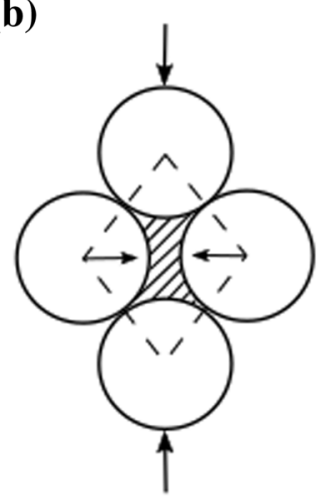

(c)

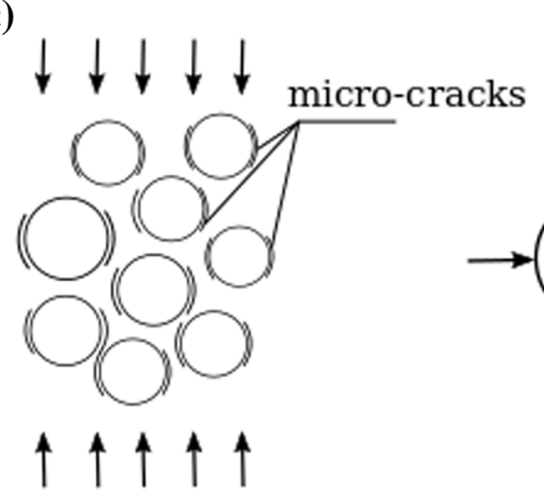

(d)

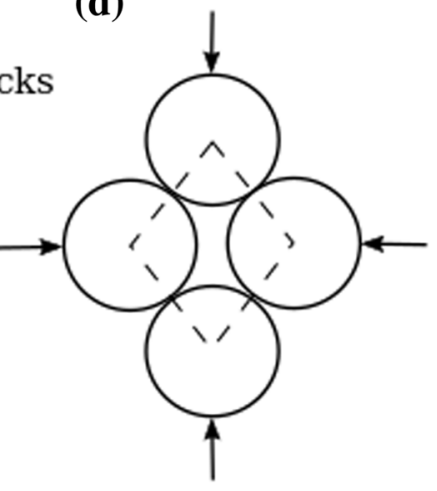

Fig. 3 Mechanism for confining concrete [2] 


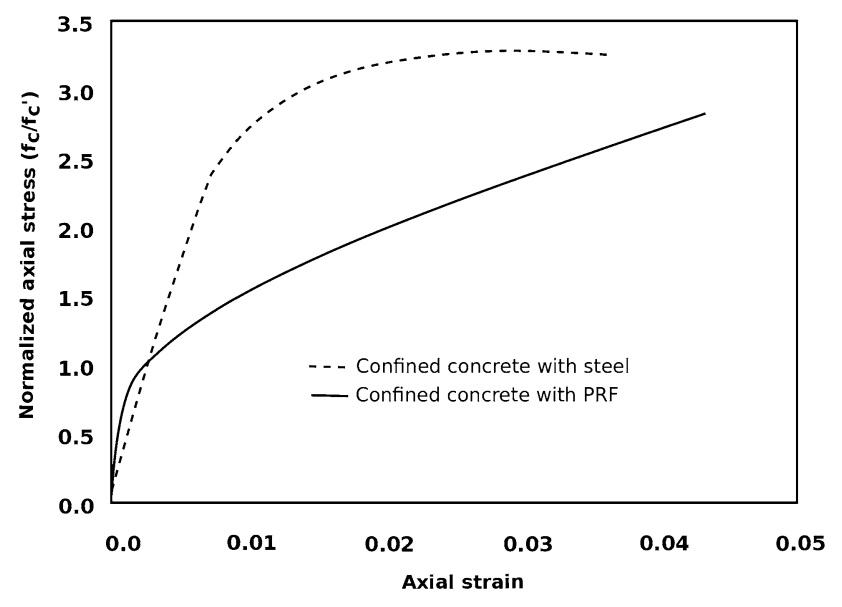

Fig. 4 Tension-deformation diagram for concrete confined with steel and with FRP [5]

with a diameter of $5.0 \mathrm{~mm}$. The bars were all produced by Gerdau. The reinforcing jackets were made using the Viapol CFW 300 Carbon composite system, which is a mantle of carbon fibers for structural reinforcement with filaments running in a single direction, which is applied with special, epoxy-based resins and has an elasticity modulus of $230 \mathrm{GPa}$ and maximum traction resistance of $4900 \mathrm{MPa}$.

\section{Instrumentation}

A hydraulic Contenco 1-3001-B manual press was used to test both the columns and the resistance of the concrete to compression. This press has a capacity for loads of up to $120 \mathrm{tf}$ (approximately $1200 \mathrm{kN}$ ) and two manometers for the measurement of the loads, one with a scale of 0-120 tf in divisions of $200 \mathrm{kgf}$ (approximately $2 \mathrm{kN}$ ), and the other with a scale of $0-24 \mathrm{tf}$ in divisions of $40 \mathrm{kgf}$. The piston has a maximum range of $35 \mathrm{~mm}$. The displacement of the test columns was measured using Gefran PY-2-F-050S01M linear variable differential transformers (LVDTs), with a range of $10-50 \mathrm{~mm}$, infinite resolution, and displacement velocity of up to $10 \mathrm{~m} / \mathrm{s}$, attached to a digital Contenco indicator with a 4-digit display, peak memory, and RS-232 connection.

\section{Methods}

\section{Production of the columns}

To determine the efficiency of the reinforcement with CFRP, all the columns were produced with the same concrete, with the exact same geometric characteristics and arrangement of internal reinforcement, so that the only practical difference among them was the arrangement of the CFRPs. All five columns thus had a length of $55.0 \mathrm{~cm}$
Table 1 Characteristics of the concrete used in the trials

\begin{tabular}{llll}
\hline $\begin{array}{l}\text { Mean } \\
\text { compressive } \\
\text { strength }(\mathrm{MPa})\end{array}$ & $\begin{array}{l}\text { Mean tensile } \\
\text { strength } \\
(\mathrm{MPa})\end{array}$ & $\begin{array}{l}\text { Initial } \\
\text { tangential } \\
\text { modulus }(\mathrm{GPa})\end{array}$ & $\begin{array}{l}\text { Drying } \\
\text { modulus } \\
(\mathrm{GPa})\end{array}$ \\
\hline 26.74 & 2.68 & 28.96 & 25.20 \\
\hline
\end{tabular}

and a square cross section of $10.0 \mathrm{~cm} \times 10.0 \mathrm{~cm}$. Two $8.0 \mathrm{~mm}$ diameter bars were molded to form the longitudinal reinforcement, with the transverse section presenting a bar in each corner (Fig. 5). The stirrups were made from bars with a diameter of $5.0 \mathrm{~mm}$. The dimensions of the columns and the arrangement of the reinforcement are shown in Fig. 5. The format of the longitudinal bars, which are similar to the stirrups, was necessary to increase the rigidity of their extremities, and improve their support.

The stirrups were spaced at a distance of $9.0 \mathrm{~cm}$ from one another, except at the extremities, where they were placed closer together, to compensate for the higher tensions caused by the loading in these areas. A covering of $1.0 \mathrm{~cm}$ was applied to all the surfaces of the columns.

In spite of the fact that the analysed columns had reduced dimensions in comparison to the majority of the real columns, it is necessary to emphasize that it was not the aim of this work to determine any correlation between reduced model and prototype through the dimensional analysis and laws of similarity. The aim has always been to compare the structural behavior of the strengthened columns (P2, P3, P4 e P5) to the one of the non-strengthened column of reference (P1).

\section{Reinforcement with CFRP}

Columns with a square cross section have a parabolic distribution of internal tension on each external surface, with an initial inclination of approximately $45^{\circ}$, which concentrates the tension in the corners and may cause the premature rupture of the CFRP jacket [9]. Given this, to increase the efficiency of the reinforcement, it is necessary to round the corners of the column before applying the composite system. Following the recommendations of the manufacturer of the system used in this study, the corners of the four test columns were rounded with an electric sander equipped with a disc for concrete, which was used to round the corners with a radius of approximately $1.0 \mathrm{~cm}$.

To analyze the efficiency of the reinforcement, the behavior of the columns under different areas of jacketing was verified, with the aim of identifying the parts of the column in which the application of the fibers was most efficient. For this, each one of the four test columns was fitted with a distinct arrangement of fibers (Fig. 6): column P2 was fitted with a central band $10.0 \mathrm{~cm}$ in width, column P3 was fitted with two bands of $10.0 \mathrm{~cm}$, column P4 with 
Fig. 5 Details of the columns (not to scale, with proportions in centimeters)
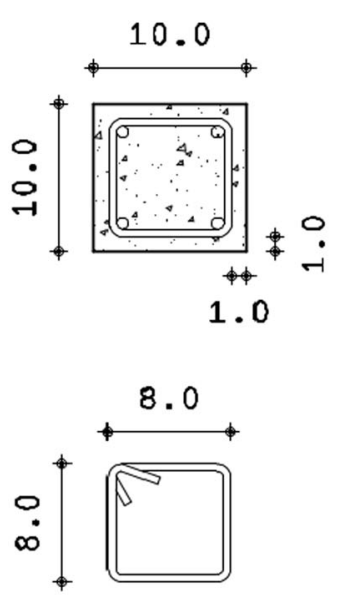

$\varnothing 5.0 \mathrm{~mm}$
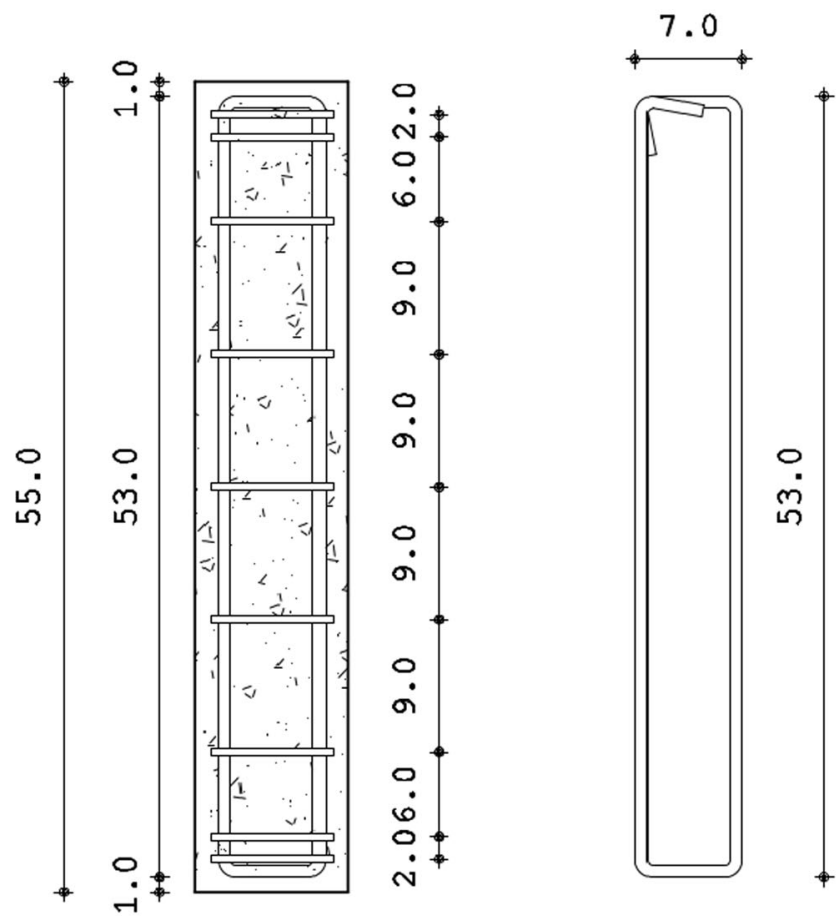

$\varnothing 8.0 \mathrm{~mm}$

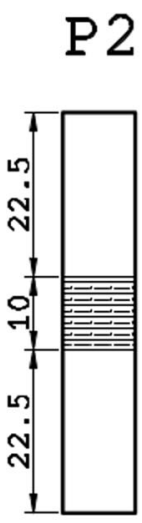

1 F1

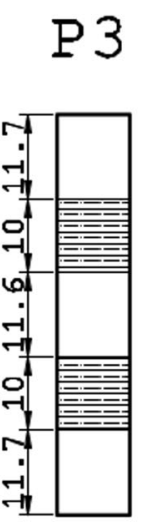

2 F1

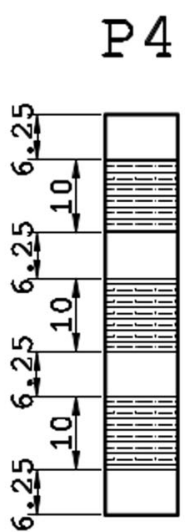

3 F1

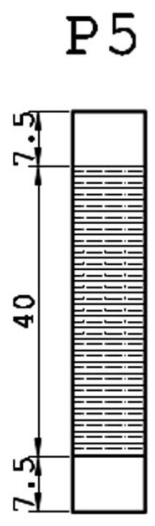

$1 \mathrm{~F} 2$
F1

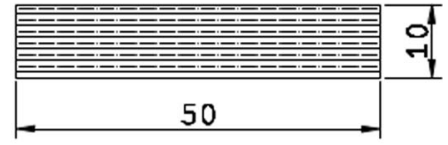

F2

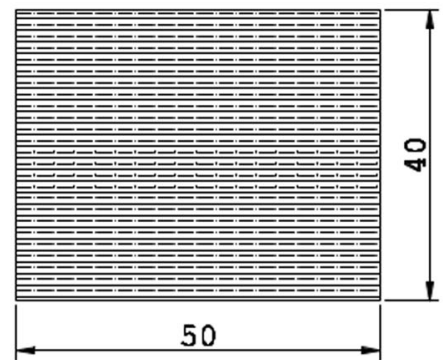

Fig. 6 Arrangement and dimensions of the CFRP mantles (not to scale, with proportions in centimeters)

three bands of $10.0 \mathrm{~cm}$, and column P5 with a single band of $40.0 \mathrm{~cm}$, all placed centrally with equidistant spacing. The mantles were $50.0 \mathrm{~cm}$ long, with $40.0 \mathrm{~cm}$ to cover the four sides of the column, and an additional $10.0 \mathrm{~cm}$ of overlap, which is necessary to guarantee the attachment of the mantle, according to the manufacturer's recommendations.

\section{Axial compression tests}

Fifteen days after the application of the CFRP composite system to the columns, and 104 days after the construction of the concrete columns, tests were run to determine the efficiency of the reinforcement applied to the models. The tests used to measure the resistance capacity of the columns consisted of the application of centralized loads to the extremities of the model columns, with the same intensity and in opposing directions, in order to produce axial compression. To achieve this, the columns were placed in the press, centralized, supported by the lower plate. A metal plate was placed on the upper extremity of the column in order to homogenize the reaction applied by the support of the press. 


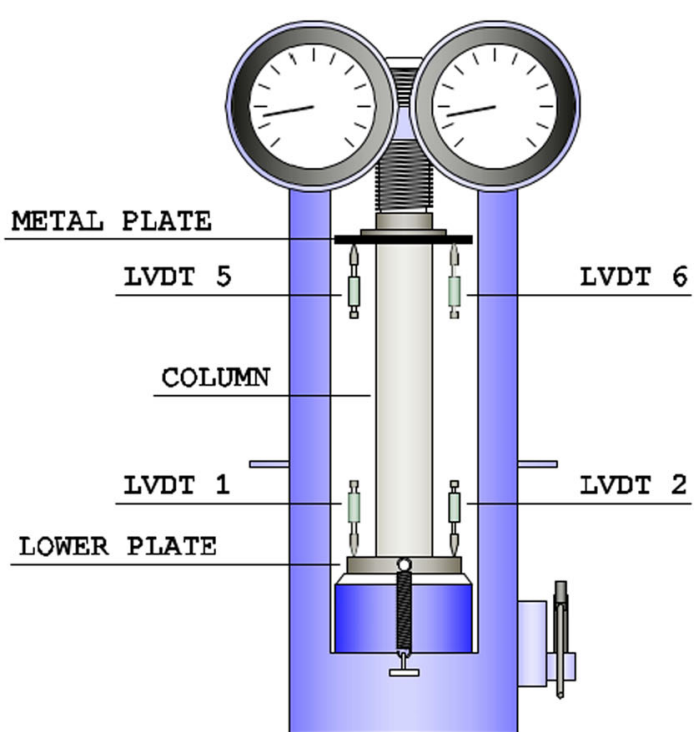

(a)

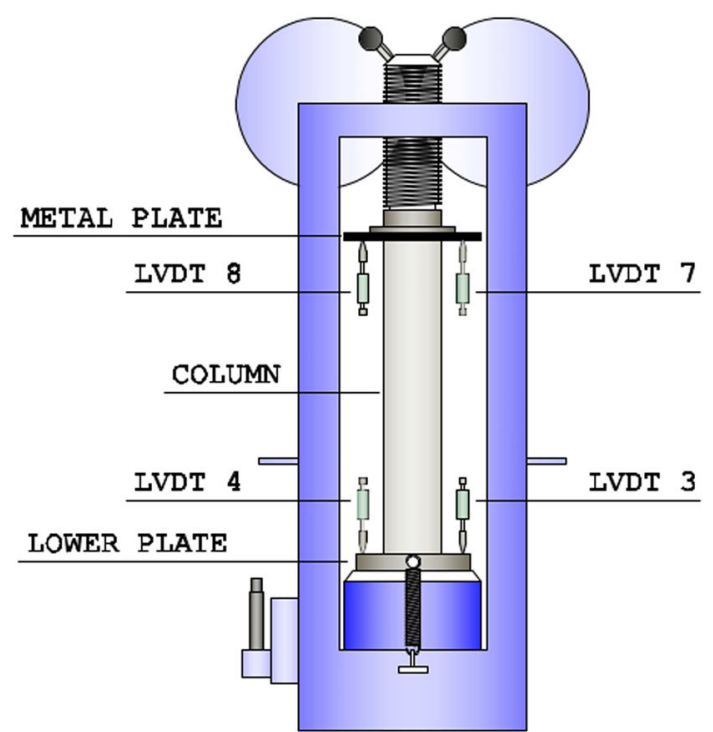

(b)

Fig. 7 Mounting of the LVDTs: a front and b back views of the press

Compression causes an axial shortening of the column, and a lateral expansion. To measure the shortening of the column, displacement transformers (LVDTs) were placed in the lower plate and the metal plate on the top of the column (Fig. 7). The difference between the values recorded at the top and bottom of the column is equal to the shortening of the column caused by axial compression. The specific deformation is found by dividing the shortening by the initial length of the column, and is used to evaluate the load-deformation behavior of the columns. Figure 8 shows column P1 positioned in the press before the test.

During the tests, the loading was increased gradually, and was interrupted at each increase of $20 \mathrm{kN}$ to permit the reading of the displacement values measured by the LVDTs. The load was increased until the column could not support the pressure and ruptured.

\section{Theoretical procedures}

The theoretical analysis consisted of the computer modeling of the columns in the Abaqus software (version 6.14), which uses the Finite Elements method to resolve a wide range of engineering problems, in order to analyse the distribution of tensions inside the columns, by aiming to understand better the behavior of the confined concrete. This analysis was complemented by the formulation of a model for the interpretation of the behavior of the columns, which evaluated the increase in resistance provided by the reinforcement, based on the strut-and-tie model.

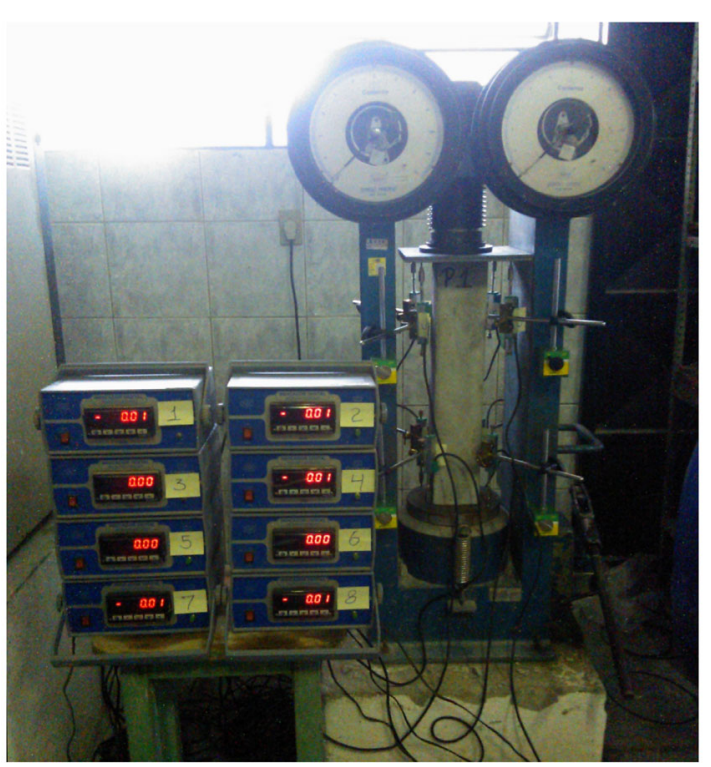

Fig. 8 Column P1 positioned in the press before the test

\section{Modeling}

The geometry of the models was produced in the Abaqus/ CAE pre-processor. A three-dimensional deformable solid $(10 \mathrm{~cm} \times 10 \mathrm{~cm} \times 55 \mathrm{~cm})$ was used to simulate the concrete body of the control column, obtained by extrusion. For the other columns, a solid with rounded corners (radius of $1.0 \mathrm{~cm}$ ) was used. The longitudinal and transverse bars were modeled as deformable three-dimensional bars represented only by their longitudinal axis to simplify the model and reduce the computation necessary for the 
analyses. The CFRP jackets were modeled as deformable three-dimensional shells obtained by extrusion, and were represented by their mean longitudinal plane, also for simplification.

The concrete-steel interface was modeled by using the tools of the module "Interaction" of Abaqus, for this, it was created a "Constraint" of the type "Embedded region", which allows to embed a region of the model inside a region "host" of the model or inside the whole model. On the other hand, the concrete-CFRP interface was modeled by using a "Constraint" of the type "Tie", which connects two surfaces so that it can restrict the displacement of one as a consequence of the presence of the other.

The steel material used for the reinforcement was defined as having generic elastic properties, with an elasticity modulus (E) of $210 \mathrm{GPa}$ and Poisson coefficient (v) of 0.3 , considered to be ductile, given it flow resistance. The CFRP material was defined with the modulus and tensile strength as defined above. The concrete material was defined according to the values obtained for the concrete used in the physical tests.

The trials were conducted by applying the rupture load to each column, as recorded in the physical tests, distributed on the upper surface of the columns, to determine the internal distribution of tensions in the models. The outline conditions were restricted to the lower surface of the models, in the three global directions, $\mathrm{X}, \mathrm{Y}$ and $\mathrm{Z}$.

\section{The strut and tie model proposed for the columns}

When a column is subjected to concentrated compressive forces, internal compressive tensions are propagated, beginning at an angle of approximately $45^{\circ}$ from the vertical, following a direction parallel to the longitudinal axis of the column. Using the load-pathway process, an ideal model composed of struts, ties and joints was used to represent a column submitted to centralized compression forces. This model is shown in Fig. 9, in which the struts at the extremities are inclined $45^{\circ}$, and are linked to joints, joining them to vertical struts and horizontal ties, which balance the vertical and horizontal components that affect the joints. In this case, the transverse reinforcement of the column absorbs the traction tensions of the ties and the concrete, which, together with the longitudinal bars, resist the compressive tensions represented by the vertical struts.

\section{Results and discussion}

\section{Axial compression tests}

Column P1, which was used as the control for comparisons with the other test columns was not strengthened,

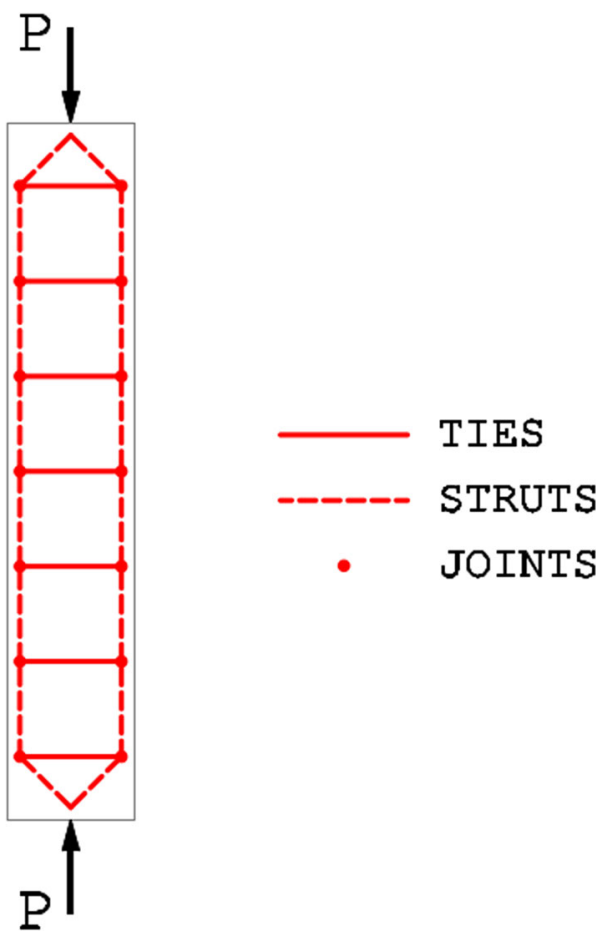

Fig. 9 Strut and tie model for columns under centered axial compression

and presented the smallest rupture load. Its failure was characterized by extensive fissuring of the concrete (Fig. 11). The break load was $350 \mathrm{kN}$ with deformation of 9.63 \%. Column P2, which had a $10 \mathrm{~cm}$ CFRP jacket in its mid-section, ruptured with extensive fissuring of the concrete in the upper part of the column, reaching a break load of $395 \mathrm{kN}$, approximately $12.86 \%$ greater than that of the control column, P1. Final deformation was $8.19 \%$. Column P3 was strengthened with two $10 \mathrm{~cm}$ CFRP jackets spaced equally along its length. This column failed with a load of $420 \mathrm{kN}, 20 \%$ greater than that of the control column and approximately $6.33 \%$ greater than the value recorded for column P2, which was cladded with half the area of jacketing. Rupture deformation was $5.65 \%$.

Column P4 had three $10 \mathrm{~cm}$ reinforcement jackets, also distributed uniformly along its length. This column failed at a load of $495 \mathrm{kN}, 41.43 \%$ greater than the control column, with final deformation of $8.24 \%$. As the CFRP jackets were closer to the extremities of the column, the fibers impeded the lateral expansion of the concrete, and the failure of the column was caused by the rupture of the lower CFRP mantle (Fig. 11), although it was the polymer resin, rather than the carbon fibers that ruptured, indicating that, if the resin were more resistant, the rupture would have occurred later. The concrete also presented fissures between the middle and lower CFRP jackets, as well as the upper extremity of the column. 
Column P5, which had the largest area of CFRP cladding (a $40 \mathrm{~cm}$ band), also had the greatest rupture load, of $500 \mathrm{kN}$, with $6.67 \%$ deformation. However, despite having $33.33 \%$ more CFRP jacketing, this column was only $1.01 \%$ more resistant than column P4. In other words, the reinforcement with three bands of CFRP (column P4) was as efficient as a single large mantle (P5), despite the fact that it covered a much larger surface area. Figure 10 shows the columns positioned in the press during the tests and, in the Fig. 11, it is possible to see them after the rupture.

Figure 12 shows the load-deformation behavior of all the columns. The Table 2 shows the failure loads $\left(\mathrm{N}_{\text {failure }}\right)$ and final deformation $\left(\varepsilon_{\mathrm{u}}\right)$ of the columns, as well as the load corresponding to a deformation of $3.50 \%\left(\mathrm{~N}_{3.50 \%}\right)$, which is considered to be the final deformation for concrete in response to compression. For this degree of deformation, an increase in the load supported by the columns was also confirmed. The values recorded for columns P4 and P5 are practically the same, which indicates that the reinforcement with jackets distributed long the column was as efficient as a single, continuous mantle. As the transverse reinforcement is the same in all the columns, it is clear that the increase in the resistance of the concrete generated by the confinement with CFRP jackets increased the resistance capacity of the column for the same degree of longitudinal deformation.

The reinforcement ratio $\left(A_{\text {reinforcement/ }} A_{\text {concrete }}\right)$ for each model is obtained by dividing the area of the reinforcement applied to each column $\left(\mathrm{A}_{\text {reinforcement }}\right)$ by the sum of the area of the lateral surfaces of the column ( $\left.\mathrm{A}_{\text {concrete }}\right)$. The ratio for each column is presented in Table 3 . The increase in the resistance capacity (IR) resulting from the CFRP jacketing can be determined by dividing the failure load $\left(\mathrm{N}_{\text {failure }}\right)$ of each column by the final load of the unstrengthened RC column, $\mathrm{N}_{\text {failure P1 }}$ (see Table 3). It is still possible to obtain a relation between the increase of the resistant capacity of each column (IR) and the biggest gain in this capacity due to the jacketing (IR of 1.428 for column P5), as shown in the Table 3.

As it can be observed by the shown values and also by analysing the graphic of Fig. 12, there was a considerable increase in the resistant capacity of the models, this increase was directly proportional to the increase of the strengthening rate of the columns. These results are similar to the ones found by Carrazedo [5], who obtained increases in the resistant capacity of short columns jacketed with CFRP between 31 and $64 \%$, in comparison to their models with no strengthening. In his work, he observed that the confinement may cause significant increases in the resistance and in the last deformation of the concrete. On the other hand, Sudano [9] obtained in his tests a bigger gain of resistance to axial compression in models with circular transversal section than with square section, but he emphasized the importance of the rounding of the edges of the square sections, as it decreases the concentration of tensions in the fibers, by ensuring the efficiency of this strengthening.

However, it is not possible to determine the ductility based only on the values of final deformation, given that the press used in the tests cannot provide a uniform longitudinal deformation, which would have been necessary to provide the data for the ductility diagram. Thus, in spite of the good results obtained with the experiments performed, more extensive tests would be necessary, as well as with a larger amount of models, so that it allows more complete analyses and with a greater abundance of details, by providing a better validation of the found values.

There is a clear positive relationship between the reinforcement ratio and the resistance capacity recorded in the
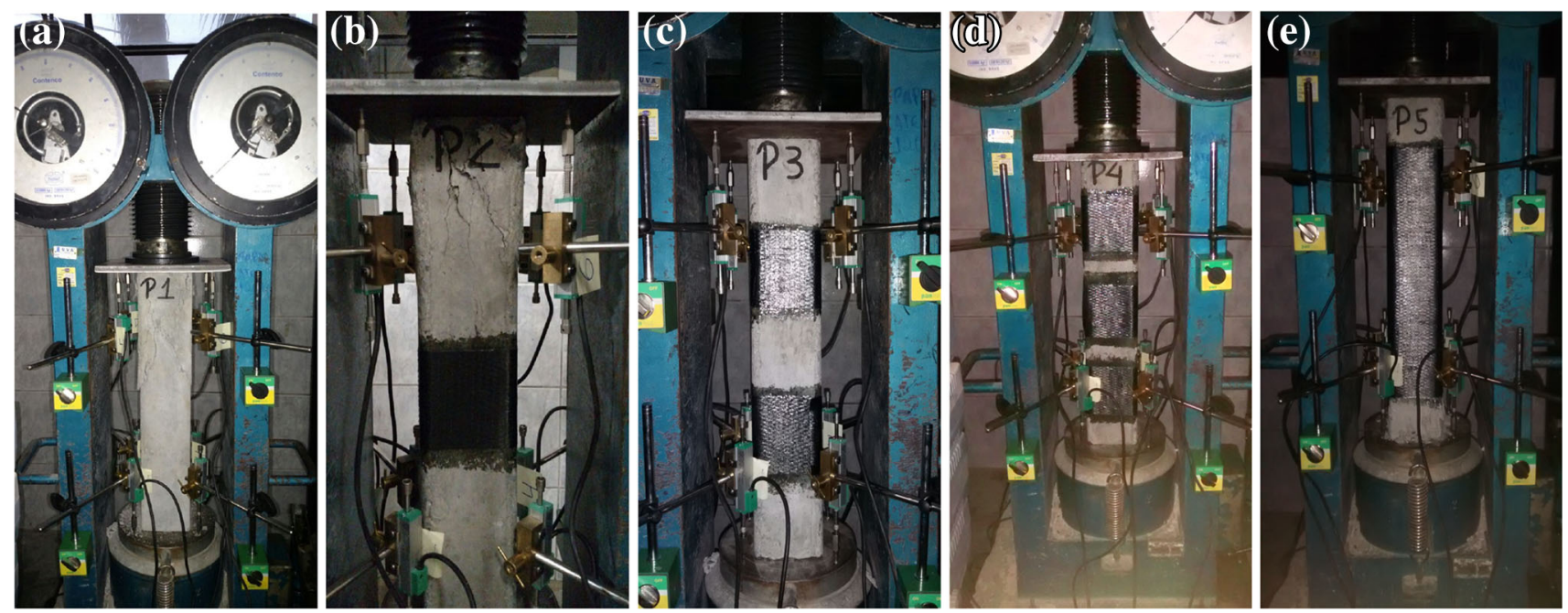

Fig. 10 Columns during the test: a P1, b P2, c P3, d P4, e P5 

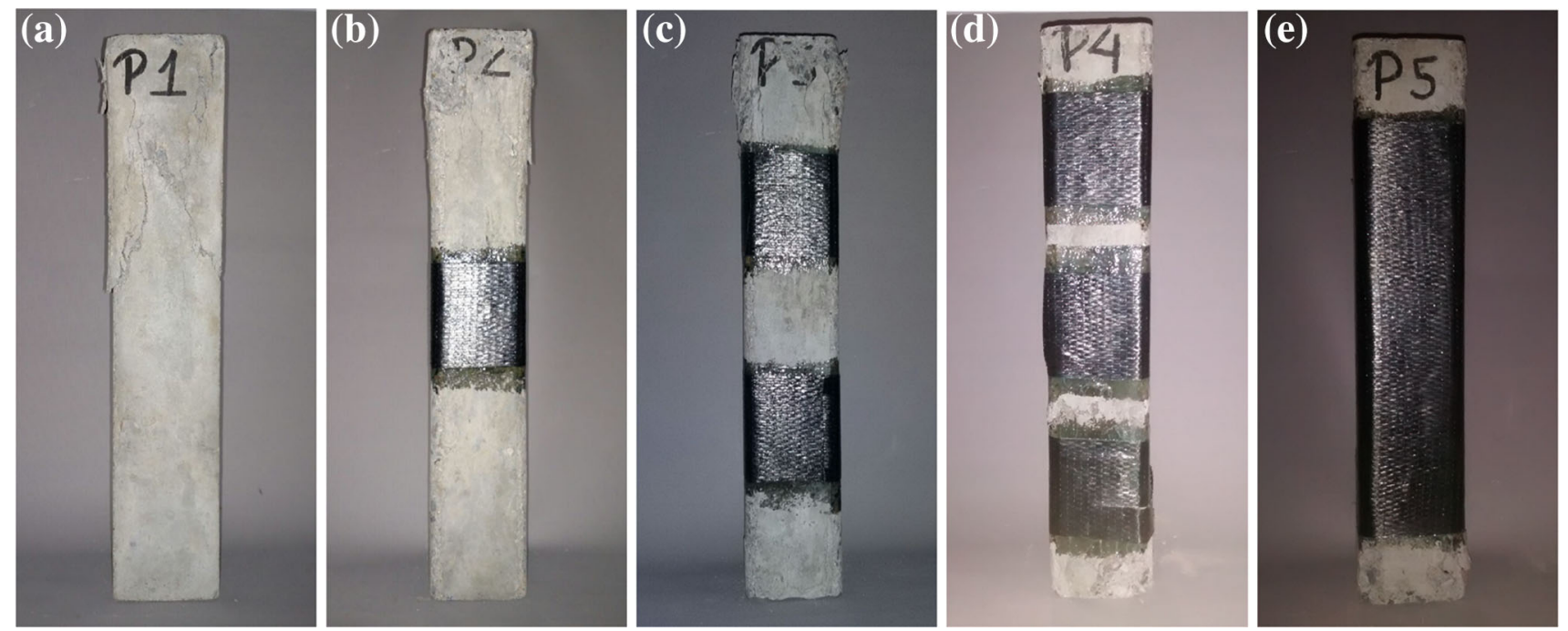

Fig. 11 Columns following failure: a P1, b P2, c P3, d P4, e P5

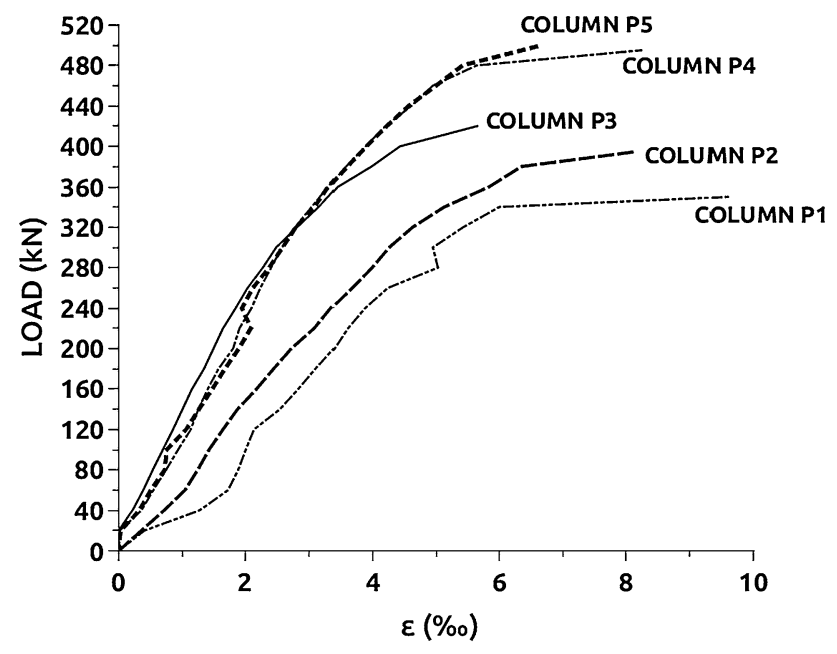

Fig. 12 Load-deformation behavior of the columns

Table 2 Results of the tests

\begin{tabular}{lllll}
\hline Column & Reinforcement & $\mathrm{N}_{\text {failure }}(\mathrm{kN})$ & $\varepsilon_{\mathrm{u}}(\%)$ & $\mathrm{N}_{3.50 \% 0}(\mathrm{kN})$ \\
\hline P1 & - & 350 & 9.63 & 210 \\
P2 & $1 \mathrm{~F} 1$ & 395 & 8.19 & 249 \\
P3 & $2 \mathrm{~F} 1$ & 420 & 5.65 & 362 \\
P4 & $3 \mathrm{~F} 1$ & 495 & 8.24 & 374 \\
P5 & 1 F2 & 500 & 6.67 & 373 \\
\hline
\end{tabular}

tests, and a non-linear regression of these data produced a second-degree polynomial function for the slope of the graph (Fig. 13). The coefficient of determination $\left(\mathrm{R}^{2}\right)$ found for the presented regression was of 0.9542 . This function permits the calculation of the increase in the resistance capacity of the strengthened column- $\mathrm{f}(\mathrm{x})-$ based on the reinforcement ratio for the column (x). It is also possible to calculate the reinforcement ratio needed to obtain a given increase in the resistance capacity of the column, by resolving the equation for a given value of $\mathrm{x}$.

As shown above, a simplified strut and tie model can provide increased resistance in a column submitted to centered axial compression, although this model does not consider the increase in resistance provided by the confinement of the concrete. Based on the function presented in Fig. 13, a coefficient (k) can be calculated using Eq. 1 (below) for the correction of the resistance capacity of the column, based on the simplified strut and tie model presented in Fig. 9. In this case, once the load (P) resisted by the column is found, this value can be multiplied by the correction coefficient $\mathrm{k}$ to obtain the maximum load that can be sustained by the column strengthened with CFRP.

$\mathrm{k}=-0.1849 \eta^{2}+0.7628 \eta+0.9933$,

where $\eta=$ the reinforcement ratio $\left(A_{\text {reinforcement } /} A_{\text {concrete }}\right)$ applied to the column, that is, the area of the CFRP bundles divided by the sum of the area of the lateral surfaces of the column.

\section{Analyses in Abaqus}

Figure 14 shows the distribution of the compressive tensions of the control column, P1. The compression of the surfaces of this column ranged from 0.0 to 35.0 $\mathrm{MPa}$, whereas in the longitudinal bars in the interior of the column, the values reached $260.0 \mathrm{MPa}$, due to the fact that the modulus of elasticity of the steel reinforcing bars is much greater than that of the concrete. The compressive tensions in the concrete in the interior of this column varied from 13.0 to $19.0 \mathrm{MPa}$ 
Table 3 Reinforcement ratios and increase in the resistance capacity of the columns

\begin{tabular}{lllllll}
\hline Column & $\mathrm{A}_{\text {reinforcement }}\left(\mathrm{cm}^{2}\right)$ & $\mathrm{A}_{\text {concrete }}\left(\mathrm{cm}^{2}\right)$ & $\mathrm{A}_{\text {reinforcement }} / \mathrm{A}_{\text {concrete }}$ & $\mathrm{N}_{\text {failure }}(\mathrm{kN})$ & $\mathrm{IR}=\mathrm{N}_{\text {failure }} / \mathrm{N}_{\text {failure P1 }}$ & $\mathrm{IR} / 1.428$ \\
\hline P1 & 0 & 2200 & 0.000 & 350 & 1.000 & 0.70 \\
P2 & 400 & 2200 & 0.182 & 395 & 1.128 \\
P3 & 800 & 2200 & 0.364 & 420 & 1.200 & 0.79 \\
P4 & 1200 & 2200 & 0.545 & 495 & 1.414 & 0.84 \\
P5 & 1600 & 2200 & 0.727 & 500 & 1.428 & 1.00 \\
\hline
\end{tabular}

Fig. 13 Relationship between the reinforcement ratio and the resistance of the material

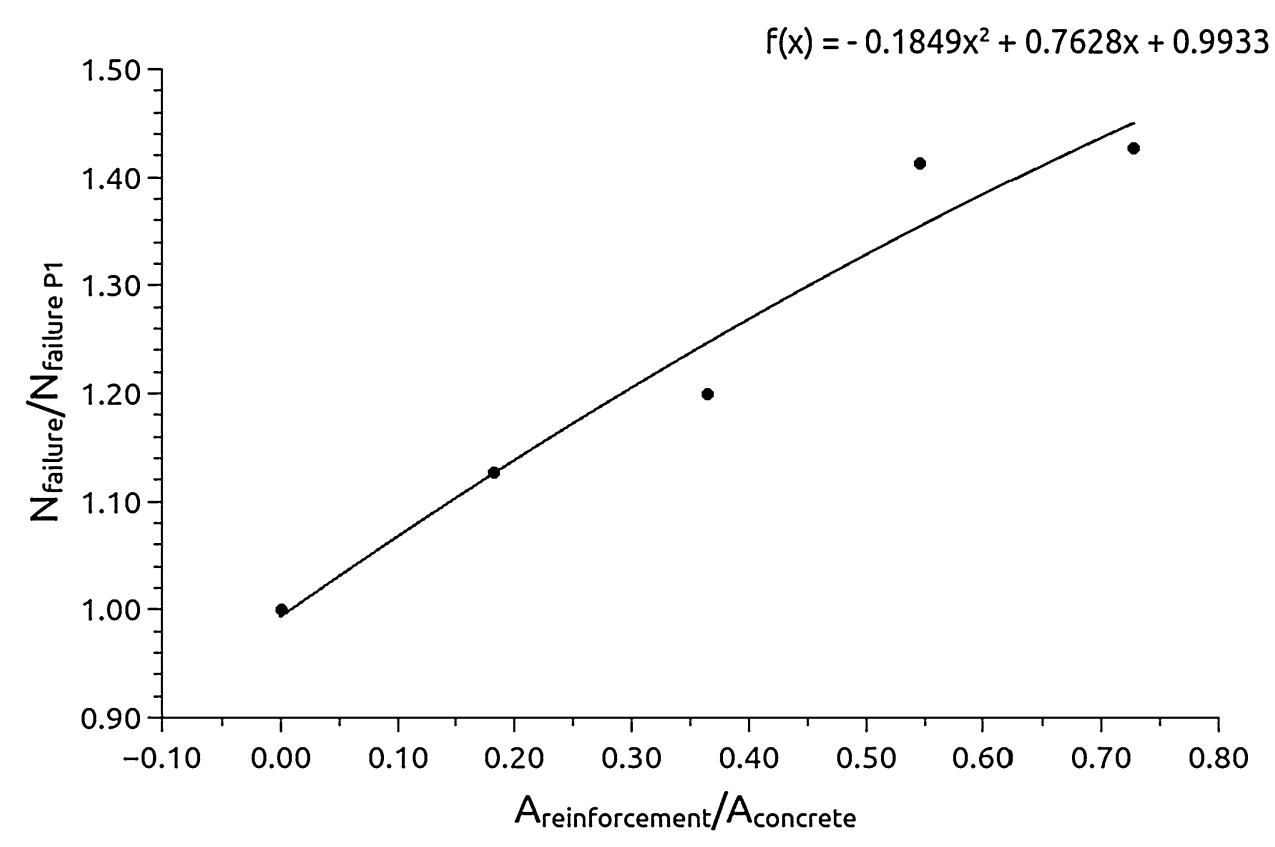

throughout most of the center of the column, reaches values of nearly $28.0 \mathrm{MPa}$ in the upper extremity, where the load was applied (Fig. 15). This value is close to that of the mean compressive strength of the concrete used to make the columns, which may account for the breakdown of the concrete in this area, as shown in Fig. 11.

Figure 16 shows the compressive tensions of the models of columns P2-P5, and the considerable similarities among them, although there is a subtle decrease in the maximum values. This value is the maximum tension acting on the longitudinal bars in the interior of the columns, and indicates a slight increase in the mobilization of the concrete with increasing reinforcement ratios. In other words, the increasing confinement of the concrete modified, albeit only slightly in these tests, the distribution of the tension inside the columns.

Figure 17 shows the distribution of the tension inside the concrete of the strengthened columns, indicating a slight modification, which can be observed in the minimum and maximum values shown in the labels. The similarities found among the models, despite the differences in the area of reinforcement, are due to the simplification of the CFRP material in the modeling and the configuration of the behavior of the concrete-CFRP interface. However, a comparison of Figs. 15 and 17 indicates that the presence of the CFRP jackets has a considerable effect on the distribution of the compressive tension inside the concrete. The confinement clearly mobilizes the concrete in the central portion of the columns, supporting a broader range of tensions, which would account for the increase in the resistance capacity of the strengthened columns in comparison with the control column.

\section{Final considerations}

The reinforcement of the columns by CFRP jacketing was extremely effective for increasing the resistance capacity of the columns submitted to axial compression. The increase in this capacity was directly proportional to the reinforcement ratio used. Reinforcement with CFRP bundles placed along the length of the column, as in column P4, is just as 
Fig. 14 Compressive tension in column P1 (values in $\mathrm{N} / \mathrm{m}^{2}$ )
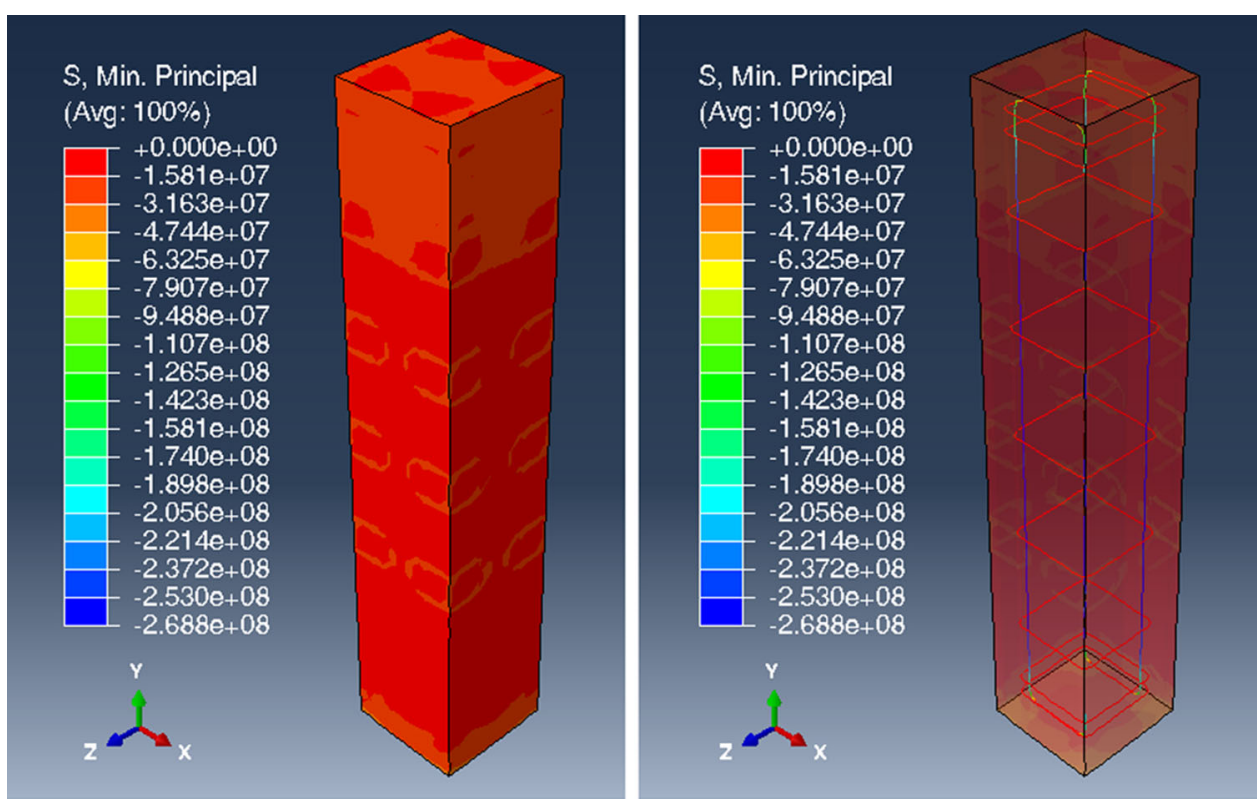
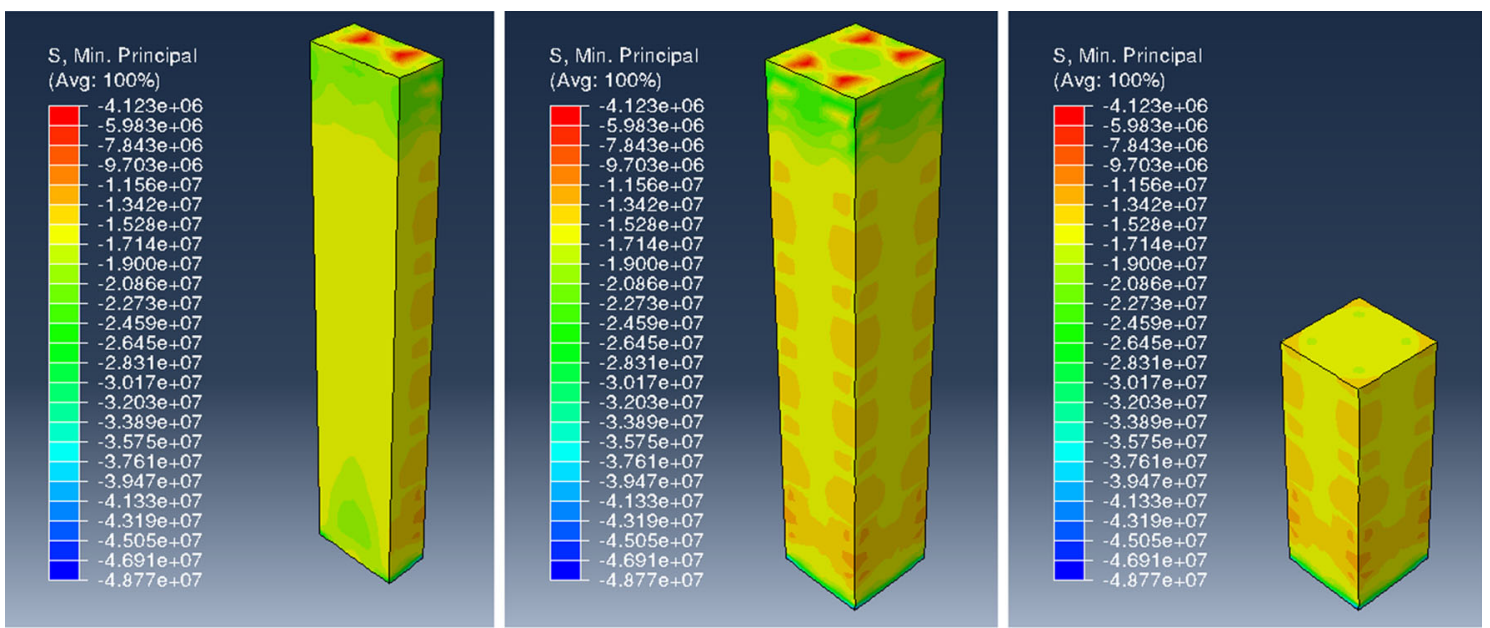

Fig. 15 Internal compressive tension in the concrete of column P1 (values in N/m²)

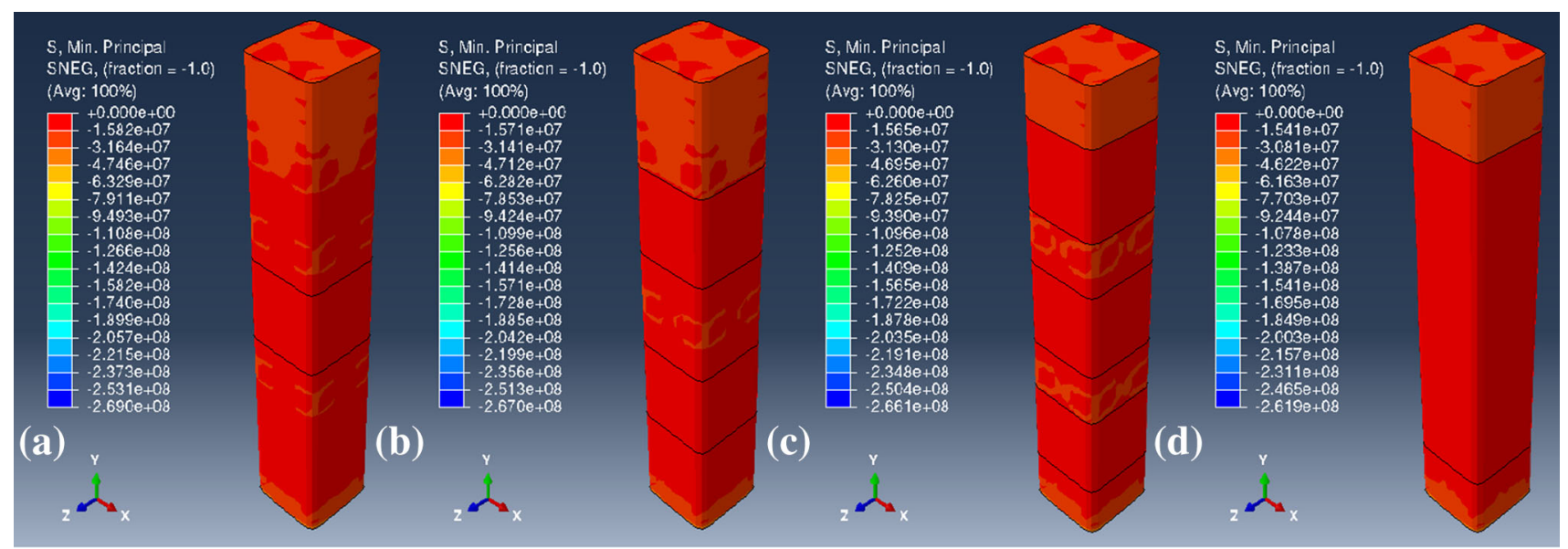

Fig. 16 Compressive tension in the columns: a P2, b P3, c P4, d P5 (values in N/m²) 


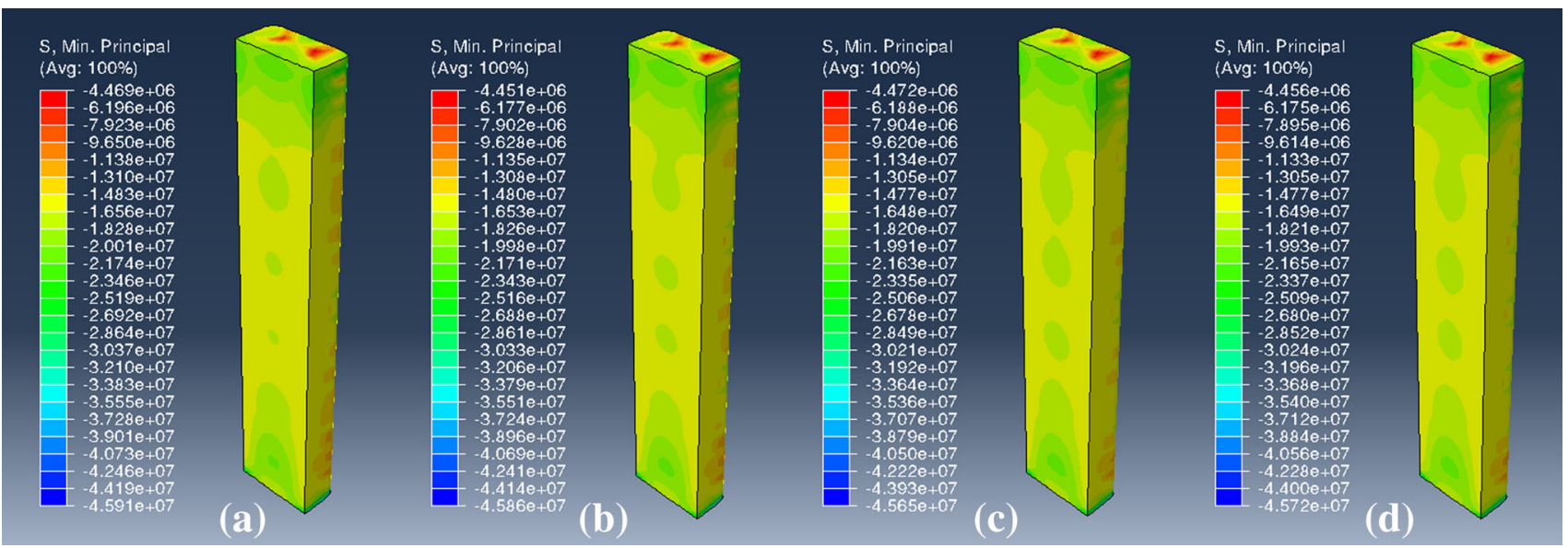

Fig. 17 Internal compressive tension in the columns: a P2, b P3, c P4 and d P5 (values in N/m²)

efficient than the reinforcement applied to column P5, which consisted of a single mantle covering most of the column, even though it had a higher reinforcement ratio.

Transverse reinforcement clearly resulted in the confinement of the concrete, increasing the ductility of the columns, with much greater final deformation than that of concrete under compression. The use of the strut and tie model, combined with the Finite Elements method, is an extremely reliable approach to the prediction of the behavior of columns subjected to compressive loads. As shown for the design of a number of different structural elements, these models can also be used for columns.

It is important to emphasize that the conclusions of this work are restricted only to the results of the tests of the five columns presented here. Other future researches, with more tests of columns, with and without strengthening, are necessary for a better validation of this research. In spite of that, it is possible to realize the big potential of application of this method of strengthening in reinforced concrete structures, as its great simplicity of execution make it economically competitive in comparison to the other more traditional methods.

Acknowledgments The authors are grateful to Viapol, the company that sponsored this research and provided the carbon fiber mantles, as well as the incentives for the development of technological advances in the design and application of the techniques of structural reinforcement, which contribute to the enrichment of Civil Engineering. They are also grateful to the Cameron construction company for providing the raw materials and labor for the production of the columns, and for its constant support for the research at GEM, which reflects the concerns and contribution of the company to the future of the Construction Industry.

\section{References}

1. Gibson RF (1994) Principles of composite material mechanics. McGraw-Hill, New York

2. Fédération Internationale du Béton-FIB (1999) Structural concrete: textbook on behaviour, design and performance. Bulletin 1(v. 1):35-37 (pp 206-212)

3. Richart FE, Brantzaeg A, Prown RL (1928) A study of the failure of concrete under combined compressive stress. Urbana: Engineering Experimental Station, University of Illinois. Bulletin n. 190

4. Balmer GG (1949) Shearing strentgh of concrete under high triaxial stress-computation of Mohr's envelope as a curve. Structural Research Laboratory Report No. SP-23. Bureau of Reclamations, United States Department of the Interior

5. Carrazedo R (2002) Mecanismos de confinamento e suas implicações no reforço de pilares de concreto por encamisamento com compósito de fibras de carbono. Masters thesis-São Carlos School of Engineering, Universidade de São Paulo, São Carlos

6. Edwards KL (1998) An overview of the technology of fibrereinforced plastics for design purposes. Mater Des 19:1-10

7. Associação Brasileira de Normas Técnicas (2007) NBR 5739: Concreto-Ensaio de compressão de corpos-de-prova cilíndricos. ABNT, Rio de Janeiro

8. Associação Brasileira de Normas Técnicas (2014) NBR 6118: Projeto de estruturas de concreto-Procedimento. ABNT, Rio de Janeiro

9. Sudano AL (2005) Influência da forma da seção transversal no confinamento de pilares de concreto armado encamisados com PRFC (polímero reforçado com fibra de carbono). Masters thesisSão Carlos School of Engineering, Universidade de São Paulo, São Carlos 